\title{
LA PROTECCIÓN DEL PATRIMONIO CULTURAL DESDE LA CONTITUCIÓN
}

POR

CARLOS RUIZ MIGUEL

Catedrático de Derecho Constitucional

de la Universidad de Santiago de Compostela

\section{PLANTEAMIENTO DE LA CUESTIÓN: CULTURA Y CONSTITUCIÓN}

La relevancia de la cultura para el Estado y la Constitución, si bien podemos considerar que existe desde que el Estado es Estado y la Constitución, Constitución, sólo en los últimos tiempos y de forma progresiva se ha explicitado. Esta relación entre la "Cultura" (de la que es una parte importante el "patrimonio cultural») y la "Constitución» se ha analizado desde diversos prismas: el análisis del Derecho Comparado, el estudio de la cultura constitucional y del problema de la Constitución cultural.

En primer lugar, el fenómeno de la inserción expresa de la cultura (y el patrimonio cultural) en los textos constitucionales ha sido objeto de estudio desde el planteamiento del Derecho Constitucional Comparado. Así se ha podido constatar por autores como Häberle la progresiva recepción de la protección de los bienes culturales en textos constitucionales europeos y americanos. Para este autor, la importancia cuantita-

1 Marcos Vaquer Caballería, Estado y Cultura: la función cultural de los poderes públicos en la Constitución Española, Editorial Centro de Estudios Ramón Areces, Madrid, 1998, p. 77-79. 
tiva de estos preceptos le ha llevado incluso a decir (lo que quizás sea exagerado) que "la protección de los bienes culturales comienza a convertirse en un elemento esencial del tipo Estado constitucional ${ }^{2}$, el llamado "Estado de cultura".

En segundo lugar, también se ha analizado esta interacción a partir de la llamada "cultura constitucional». Desde esta perspectiva, frente a la consideración puramente normativista de la Constitución (como la de Kelsen) o esencialmente política (como la de Schmitt) se opone (o añade) una nueva noción de Constitución entendida como un producto de la cultura constitucional. Así para Häberle la Constitución es la "expresión de un determinado nivel de desarrollo cultural, ... expresión de la autorrepresentación cultural de un pueblo, espejo de su patrimonio cultural y fundamento de sus esperanzas ${ }^{3}$. Nosotros, en otro lugar, hemos indicado que se puede argumentar que la idea de Constitución es la expresión de una determinada cultura y que incluso las diferentes Constituciones son las expresiones de determinadas culturas ${ }^{4}$. Desde esta perspectiva, el estudio de la cultura es previo a la Constitución ya que ésta encuentra su explicación en aquélla. Aquí la cultura está al servicio de la Constitución.

En tercer lugar, esta interrelación se puede exponer desde un planteamiento inverso al anterior, a saber, estimando que la Constitución es previa a esa cultura (o a esa protección del "patrimonio cultural»), es la fuente de la misma, de suerte que es la Constitución la que está al servicio de la cultura. Desde esta perspectiva se habla de "Constitución cultural» o de "Constitucionalismo cultural»".

En este trabajo partiremos de este último enfoque. Lo que queremos saber es cómo la Constitución protege la cultura y, en especial, una faceta de ésta, el patrimonio cultural.

\section{EL PATRIMONIO CULTURAL DESDE LA TEORÍA DE LAS NORMAS CONSTITUCIONALES}

El estudio jurídico de la Constitución ha llevado a concluir que esa norma jurídica llamada "Constitución» dista de ser homogénea. Debe

2 Peter HäBERLE, "La protección constitucional y universal de los bienes culturales: un análisis comparativo", $R E D C$, n. ${ }^{\circ} 54$ (1998), p. 11 ss. (p. 23).

3 Peter HÄBERLE, Verfassungslehre als Kulturwissenschaft, Duncker und Humblot, Berlín, 1982, p. 19.

${ }^{4}$ Carlos Ruiz Mıguel, "Multiculturalismo y Constitución", Cuadernos Constitucionales de la Cátedra Fadrique Furió Ceriol, n. ${ }^{\circ}$ 36/37 (2001), p. 5 ss. (p. 10 ss.).

5 Ruiz Miguel, "Multiculturalismo...», cit., p. 10 y 17 ss. 
recordarse a este respecto el dato fundamental de que la Constitución es, sí, una norma jurídica, pero una norma jurídica peculiar en la que los efectos jurídicos "se ven matizados de ordinario por un complicado sistema de reenvíos y de normas interpuestas que completan las sumariedad inicial del texto en un grado cuantitativa y cualitativamente más intenso que el que se utiliza en las normas ordinarias» ${ }^{6}$. El resultado es que dentro de la Constitución existen muy diferentes tipos de normas constitucionales. Podemos hallar así normas que son "principios", "fines del Estado", "derechos", "deberes", "garantías institucionales", «normas de organización», "competencias», "mandatos al legislador y a los poderes públicos". Pues bien, Ilama poderosamente la atención que el fenómeno de la cultura en sentido amplio (comprendiendo, por tanto, al "patrimonio cultural») se halla tratado en la Constitución a través de casi todos los tipos de normas constitucionales existentes.

2.A. La cultura como «fin del Estado». Una norma que establece un fin del Estado persigue la consecución de un objetivo en la mayor medida posible, pero sin determinar hasta qué punto ni qué consecuencias tendría la no consecución del fin perseguido. Varios preceptos constitucionales configuran la cultura como uno de los "fines" que debe perseguir el Estado. Podemos citar a este respecto, el Preámbulo y los arts. 3, 9.2, 44.1, 46, 48 y 50 de la Constitución.

El Preámbulo constitucional, en dos ocasiones, habla de ello. Así, dispone que "la Nación española, ..., proclama su voluntad de: (...)», por un lado, " proteger a todos los españoles y pueblos de España en el ejercicio de (...), sus culturas y tradiciones, lenguas e instituciones" $y$, por otro, "promover el progreso de la cultura (...) para asegurar a todos una digna calidad de vida".

El art. 3.3 CE dice que "la riqueza de las distintas modalidades lingüísticas de España es un patrimonio cultural que será objeto de especial respeto y protección".

Por su parte, el art. 9.2 CE establece que: «corresponde a los poderes públicos (...) facilitar la participación de todos los ciudadanos en la vida (...), cultural». Prácticamente lo mismo, pero en relación a los jóvenes es lo que prescribe el art. $48 \mathrm{CE}$ : «los poderes públicos promoverán las condiciones para la participación libre y eficaz de la juventud en el desarrollo (...) cultural».

6 Alejandro Nieto García, "Peculiaridades jurídicas de la norma constitucional», Revista de Administración Pública, n. ${ }^{\circ} 100-102$ (1983), p. 371 ss. (p. 399). 
En relación con los ancianos, el art. 50 CE dice que «los poderes públicos (...) promoverán su bienestar (de los ciudadanos de la tercera edad) mediante un sistema de servicios sociales que atenderán sus problemas específicos de (...) cultura».

Con carácter general el art. 44.1 CE declara que "los poderes públicos promoverán y tutelarán el acceso a la cultura, a la que todos tienen derecho" (cursiva mía). Ahora bien, este del 44.1 CE es sólo aparentemente un "derecho" pues carece de mecanismos subjetivos de garantía (no es posible realizar una instancia administrativa ni una demanda ante los tribunales para hacerlo respetar). Este "derecho" sólo puede hacerse valer a través de medios objetivos (como el recurso de inconstitucionalidad contra una ley que no respete ese "derecho"). Por ello, a pesar de ser calificado como "derecho", en realidad estamos ante un "fin del Estado". Y, en efecto, el art. 53.3 CE dice que "el reconocimiento, el respeto y la protección de los principios reconocidos en el Capítulo Tercero (y el art. 44 está en ese capítulo), informará la legislación positiva, la práctica judicial y la actuación de los poderes públicos. Sólo podrán ser alegados ante la Jurisdicción ordinaria de acuerdo con lo que dispongan las leyes que los desarrollen".

Como norma de fines del Estado debe mencionarse también un precepto que alude expresamente al patrimonio cultural, el art. $46 \mathrm{CE}$, según el cual: "los poderes públicos (...) promoverán el enriquecimiento del patrimonio histórico, cultural y artístico de los pueblos de España y de los bienes que lo integran, cualquiera que sea su régimen jurídico y su titularidad. La ley penal sancionará los atentados contra este patrimonio". Resulta llamativo que este artículo aluda al patrimonio histórico, cultural y artístico "de los pueblos de España" como si el "pueblo español" (al que alude el art. 1.2 CE) en cuanto tal no tuviera su propio patrimonio histórico, cultural y artístico. De ser así, el "patrimonio cultural, artístico y monumental español" del que habla el art. 149.1.28 no sería sino el patrimonio de "los pueblos de España». Parece que nos encontramos aquí ante una concesión a las fuerzas nacionalistas centrífugas que a nuestro juicio resulta desafortunada. En efecto, parece que con ello se quiere dar a entender que España, como tal, sólo es una realidad "política», pero no "cultural» e "histórica».

2.B. La cultura como "mandato al legislador y a los poderes públicos estatales». Finalmente, la cultura aparece en la Constitución como un "mandato al legislador y a los poderes públicos» del Estado central en en su art 149.2 CE, según el cual «sin perjuicio de las competencias que podrán asumir las Comunidades Autónomas, el Estado considerará el servicio de la cultura como deber y atención esencial». Cabría 
preguntarse si lo que encontramos aquí es un "mandato" al legislador y a los poderes públicos o es un "fin del Estado". La primera diferencia entre ambos tipos de normas estribaría en que mientras las normas de "fines del Estado" vinculan genéricamente a todos los poderes públicos de cualesquiera administraciones, aquí nos hallaríamos ante un mandato específico dirigido a unos poderes públicos en particular, a saber, el Ejecutivo y Legislativo estatales. Además, en segundo lugar, mientras un "fin del Estado" no establece la consecuencia de la norma, un "mandato a la Administración y al legislador estatales" sí: concretamente, la potestad y consiguiente competencia para legislar y gestionar en una materia de este tipo. El cumplimiento de este mandato constituye así un título competencial en favor del Estado, si bien no estamos ante una competencia "exclusiva" pues nada impediría que un Estatuto de autonomía también estableciera que el "servicio de la cultura" fuese un "deber" para sus órganos de autogobierno.

2.C. La cultura como "garantía institucional». El art. 46 CE dispone que «los poderes públicos garantizarán la conservación (...) del patrimonio histórico, cultural y artístico de los pueblos de España y de los bienes que lo integran, cualquiera que sea su régimen jurídico y su titularidad. La ley penal sancionará los atentados contra este patrimonio». La comprensión de la cláusula que garantiza la conservación del patrimonio cultural como una "garantía institucional» significaría que el nivel alcanzado por el ordenamiento para la protección del patrimonio cultural no podría ser reducido pues la normativa que suprimiera o redujera tal nivel sería inconstitucional.

2.D. La cultura como "derecho". La cultura es considerada como un derecho en el art. 25.2 CE. En él se prescribe que «el condenado a pena de prisión (...) en todo caso, tendrá derecho (...) al acceso a la cultura». Por su ubicación sistemática, parece que nos encontramos ante un auténtico derecho fundamental dotado de las máximas garantías del ordenamiento. Este derecho se halla desarrollado en la ley general penitenciaria en sus arts. 24, 25.2, 56 y $57^{7}$. No deja de ser paradójico a

7 Ley Orgánica 1/1979, de 26 de septiembre, General Penitenciaria. Artículo 24: "Se establecerán y estimularán, en la forma que se señale reglamentariamente, sistemas de participación de los internos en actividades o responsabilidades de orden (...)cultural». Artículo 25.2: "El tiempo se distribuirá de manera que se garanticen ocho horas diarias para el descanso nocturno y queden atendidas las necesidades espirituales y físicas, las sesiones de tratamiento y las actividades formativas laborales y culturales de los internos".Artículo 56.1: "La Administración organizará las actividades educativas, culturales y profesionales de acuerdo con el sistema oficial, de manera que los internos puedan alcanzar las titulaciones correspondientes". 
este respecto que un criminal pueda tener un acceso a la cultura que está vedado a muchos ciudadanos. Ciertamente, es loable que se trate de "reeducar» a un criminal para que no vuelva a cometer delitos; pero puede ser un sarcasmo que ese criminal pueda llegar a tener medios culturales gratuitos que quizá no pueda tener la víctima de su delito.

2.E. La cultura como "norma de organización». La cultura es también considerada en la Constitución como una norma de organización del Estado. Así se desprende del art. 143.1 CE según el cual «en el ejercicio del derecho a la autonomía reconocido en el artículo 2 de la Constitución, las provincias limítrofes con características históricas culturales y económicas comunes, los territorios insulares y las provincias con entidad regional histórica podrán acceder a su autogobierno y constituirse en Comunidades Autónomas». La existencia de una cultura "común»fue así erigida en criterio para organizar el mapa autonómico.

2.F. La cultura como "competencia». La cultura es considerada como materia objeto de "competencia» en tres preceptos constitucionales: los arts. $148.1 .17^{\circ}, 149.1 .28^{\circ}$ y $149.2 \mathrm{CE}$. El art. $148.1 .17^{\circ}$ atribuye a las Comunidades Autónomas la posibilidad de asumir competencias en la materia de "fomento de la cultura, de la investigación y, en su caso, de la enseñanza de la lengua de la Comunidad Autónoma». Y, en efecto, todas las Comunidades Autónomas han asumido dicha competencia. En el caso de Castilla y León esto se hizo en el art. 32.1.12 de su Estatuto $^{8}$ que considera como competencia "exclusiva" de la Comunidad la materia "patrimonio histórico, artístico, monumental, arqueológico, arquitectónico y científico de interés para la Comunidad, sin perjuicio de la competencia del Estado para su defensa contra la exportación y la expoliación". Y es que, en efecto, a pesar de que los Estatutos hablen de competencia "exclusiva" no existe tal exclusividad. El alcance de esta competencia autonómica se halla determinado por el ámbito de la competencia del Estado en la materia que se establece en dos artículos, el $149.1 .28^{\circ}$ y el 149.2 .

Según el primero de ellos, el Estado tiene competencia exclusiva sobre "defensa del patrimonio cultural, artístico y monumental español

Artículo 57: «En cada establecimiento existirá una biblioteca provista de libros adecuados a las necesidades culturales y profesionales de los internos, quienes además podrán utilizar los libros facilitados por el servicio de bibliotecas ambulantes establecido por la administración o entidades particulares con el mismo fin".

8 Ley Orgánica 4/1983, de 25 de febrero, Estatuto de Autonomía de Castilla y León. 
contra la exportación y la expoliación; museos, bibliotecas y archivos de titularidad estatal, sin perjuicio de su gestión por parte de las Comunidades Autónomas". Esto significa que si bien el Estado puede legislar sobre estas cuestiones, la Comunidad Autónoma puede asumir competencias de "gestión" (esto es, ejecutivas) al respecto.

En el segundo, el 149.2, se dispone que «sin perjuicio de las competencias que podrán asumir las Comunidades Autónomas, el Estado (...) facilitará la comunicación cultural entre las Comunidades Autónomas, de acuerdo con ellas". Esto significa que el Estado también tiene atribuida una competencia para coordinar a las CC.AA. en el "servicio de la cultura" aunque ello no signifique privar a las CC.AA. de sus competencias en esa materia.

\section{EL PATRIMONIO CULTURAL Y EL SISTEMA DE FUENTES: INTERACCIÓN DEL DERECHO NACIONAL CON EL DERECHO INTERNACIONAL}

Aunque la Constitución del Estado regula lo relativo a la cultura y, en concreto, al patrimonio cultural, esto no significa que sea la única norma que lo hace. En efecto, existen varios tratados internacionales, en los que el Estado Español ha cooperado o que ha suscrito, que también prestan atención al fenómeno cultural. Estos tratados son de tres clases: de ámbito universal, de tipo regional y de carácter bilateral.

3.A. Entre los tratados de ámbito universal ratificados por España que tratan sobre la materia cultura hay que destacar el Pacto Internacional de Derechos Económicos, Sociales y Culturales y dos convenios efectuados bajo los auspicios de la UNESCO.

3.A.a. El Pacto Internacional de Derechos Económicos, Sociales y Culturales ${ }^{9}$ hace referencia a la cultura en tres de sus preceptos: los arts. 15.1.a, 15.2, 15.4. Tras reconocer "los beneficios que derivan del fomento y desarrollo de la cooperación y de las relaciones internacionales en cuestiones científicas y culturales" (art. 15.4), el Pacto Internacional establece que "los Estados partes en el presente Pacto reconocen el derecho de toda persona a: participar en la vida cultural» (art. 15.1.a). A tal efecto, "entre las medidas que los Estados partes en el presente Pacto deberán adoptar para asegurar el pleno ejercicio de

9 Pacto Internacional de Derechos Económicos, Sociales y Culturales, hecho en Nueva York el 19 de diciembre de 1966. 
este derecho figurarán las necesarias para la conversación, el desarrollo y la difusión de la ciencia y de la cultura»(art. 15.2). El "derecho» a participar en la vida cultural que se establece en este tratado presenta el problema de que no está adecuadamente garantizado ya que, lo único que establece este convenio es que "los Estados partes en el presente Pacto se comprometen a presentar, en conformidad con esta Parte del Pacto, informes sobre las medidas que hayan adoptado, y los progresos realizados, con el fin de asegurar el respeto a los derechos reconocidos en el mismo" (art. 16.1). La ley de patrimonio histórico española, efectivamente, ha adoptado las medidas oportunas para hacer efectivo este derecho al establecer un "derecho de visita pública», gratuita sobre los bienes del patrimonio ${ }^{10}$.

3.A.b. En el marco de la UNESCO existen dos tratados importantes: el convenio para la protección de los bienes culturales en caso de conflicto armado y el convenio de protección mundial cultural y natural ${ }^{11}$. El Convenio para la Protección de los Bienes Culturales en caso de conflicto armado $^{12}$ no establece un "derecho" a la cultura, sino un mandato al Estado para que adopte las medidas convenientes para hacer efectiva esa protección buscada en el convenio (arts. 3 a 7, especialmente). Lo mismo sucede en el otro texto digno de consideración es la Convención de 23 de noviembre de 1972, de Protección del patrimonio Mundial Cultural y Natural ${ }^{13}$. En esta convención se establece claramente un mandato al Estado para que "haga todo lo posible» para alcanzar el fin perseguido que es la protección de ese patrimonio (arts. 4

10 Ley 16/1985, de 25 de junio, del Patrimonio Histórico: art. 13.2 («los propietarios $y$, en su caso, los titulares de derechos reales sobre tales bienes, o quienes los posean por cualquier título, están obligados a permitir y facilitar su inspección por parte de los organismos competentes, su estudio a los investigadores, previa solicitud razonada de éstos, y su visita pública, en las condiciones de gratuidad que se determinen reglamentariamente, al menos cuatro días al mes, en días y horas previamente señalados. El cumplimiento de esta última obligación podrá ser dispensado total o parcialmente por la Administración competente cuando medie causa justificada").

${ }^{11}$ Cfr. Luis Martín Rebollo, "Bienes culturales y Comunidad Europea», en Mario P. Chiti (coord.), Beni culturali e Comunità Europea, Giuffrè, Milán, 1994, p. 37 ss. (p. 78-81).

12 Convenio para la Protección de los Bienes Culturales en caso de conflicto armado, firmado en la Haya el 14 de mayo de 1954, ratificado por Instrumento de 9 de junio de 1960. (BOE número 282 de 24 de noviembre de 1960).

13 Convención de 23 de noviembre de 1972, de Protección del Patrimonio Mundial Cultural y Natural, aceptada por Instrumento de 18 de marzo de 1982, (BOE número 156, de 1 de julio de 1982). 
y 5). A tal efecto, se establece un procedimiento de seguimiento de las obligaciones del Estado mediante la obligación de presentar informes anuales, como vimos que sucedía con el Pacto Internacional de 1966, (art. 29). Este texto, no obstante, presenta dos notas importantes. En primer lugar, establece un fondo económico para financiar las solicitudes que presenten los Estados para proteger bienes de su patrimonio.En segundo lugar, incluye una "cláusula federal" que puede ser aplicable a España en virtud de la cual este convenio se aplica también en los componentes de los Estados no unitarios (art. 34) lo cual crea una competencia estatal de, al menos, supervisión sobre los componentes territoriales del Estado para que los mismos cumplan las obligaciones internacionalmente asumidas.

3.B. Entre las normas de alcance regional, encontramos dos tipos de normas: las aprobadas en el marco del Consejo de Europa y las del Derecho Comunitario.

3.B.a. En el marco del Consejo de Europa existe una abundantísima producción normativa en materia de protección de la cultura ( $y$, en particular, del patrimonio cultural) ${ }^{14}$. Además de las Recomendaciones (del Comité de Ministros y de la Asamblea parlamentaria del Consejo de Europa) y de las Resoluciones de esos órganos, bajo los auspicios del Consejo de Europa se han aprobado cinco convenios internacionales sobre la materia que aquí nos ocupa, que son los textos más importantes desde el punto de vista normativo. Se trata del Convenio Cultural Europeo de 19 de diciembre de 1954, el Convenio Europeo para la protección del patrimonio arqueológico de 6 de mayo de 1969, el Convenio Europeo sobre las infracciones cometidas contra bienes culturales de 23 de mayo de 1985 (no firmado ni, por ende, ratificado por España), el Convenio para la protección del patrimonio arquitectónico de Europa de 3 de octubre de 1985 y el Convenio Europeo para la protección del patrimonio arqueológico de 16 de enero de 1992 (firmado, pero no ratificado por España). Todos estos convenios establecen mandatos para los poderes públicos del Estado supervisables mediante la obligación de los Estados de enviar informes periódicos sobre el grado de cumplimiento de las disposiciones del convenio respectivo.

${ }^{14}$ Consúltese la espléndida obra dirigida por Fernando MORENO DE BARREDA, El Patrimonio cultural en el Consejo de Europa. Textos, conceptos y concordancias, Hispania Nostra/Boletín Oficial del Estado, Madrid, 1999. Ver también: http://www.coe.int/T/E/Cultural_Co-operation/Heritage/Resources/RefTxtCultHer.asp\#T opOfPage 
3.B.b. Por su parte, en el marco del Derecho Comunitario Europeo también existen disposiciones sobre materia cultural que delimitan las "competencias" de los Estados y de la Comunidad Europea. Estas normas se hallan tanto en el Derecho Comunitario originario como en el derivado ${ }^{15}$.

En el Derecho Comunitario originario encontramos tres preceptos sobre la cuestión: los arts. 30, 87.3 y 151 del Tratado de la Comunidad Europea.

En primer lugar, el art. 30 del Tratado constitutivo de la Comunidad Económica Europea (versión consolidada) dispone que «las disposiciones de los artículos 28 y 29 (que establecen la prohibición de establecer entre los Estados miembros restricciones cuantitativas a la importación o a la exportación) no serán obstáculo para las prohibiciones o restricciones a la importación, exportación o tránsito justificadas por razones de (...) protección del patrimonio artístico, histórico o arqueológico nacional», si bien "tales prohibiciones o restricciones no deberán constituir un medio de discriminación arbitraria ni una restricción encubierta del comercio entre los Estados miembros". EI TCEE pretende establecer un «libre mercado europeo». De ahí el significado de este art. 30, a saber, excluir a los bienes del patrimonio cultural del libre mercado.

En segundo lugar, el art. 87.3.d TCEE señala que podrán considerarse compatibles con el mercado común "las ayudas destinadas a promover la cultura y la conservación del patrimonio, cuando no alteren las condiciones de los intercambios y de la competencia en la Comunidad en contra del interés común". Esto significa que son lícitas, para el ordenamiento comunitario, las medidas de fomento en materia de cultura y patrimonio que adopten los Estados. EI TCEE pretende que ese libre mercado europeo que se quiere establecer se halle gobernado por las leyes de la libre competencia sin prácticas desleales que la puedan perturbar, como las subvenciones públicas. En tanto en cuanto los bienes del patrimonio cultural están excluidos del libre mercado, es coherente admitir en este terreno la práctica de las subvenciones y ayudas de Estado.

Finalmente, en tercer y último lugar, el art. 151 TCEE establece una competencia en favor de la CEE para que ésta contribuya "al floreci-

${ }^{15}$ Cfr. José María A. Magán Perales, La circulación ilícita de bienes culturales, Lex Nova, Valladolid, 2001, p. 311 ss. Anteriormente, Luis Martín Rebollo, "Bienes culturales y Comunidad Europea", en Mario P. Chiti (coord.), Beni culturali e Comunità Europea, cit., p. 37 ss. y Marcos VAQUeR CABALleRía, Estado y Cultura: la función cultural de los poderes públicos en la Constitución Española, cit., p. 153 ss. 
miento de las culturas de los Estados miembros, dentro del respeto de su diversidad nacional y regional, poniendo de relieve al mismo tiempo el patrimonio cultural común». Ahora bien, esta competencia atribuye a la Comunidad Europea únicamente la posibilidad de llevar a cabo acciones de "fomento" en apoyo a los Estados. Por eso se estipula que "la acción de la Comunidad favorecerá la cooperación entre Estados miembros y, si fuere necesario, apoyará y completará la acción de éstos en los siguientes ámbitos: la mejora del conocimiento y la difusión de la cultura y la historia de los pueblos europeos, la conservación y protección del patrimonio cultural de importancia europea, los intercambios culturales no comerciales, la creación artística y literaria, incluido el sector audiovisual». Precisamente porque la competencia atribuida a la Comunidad es únicamente de fomento, en virtud de la misma la Comunidad sólo puede actuar "por unanimidad" y "con exclusión de toda armonización de las disposiciones legales y reglamentarias de los Estados miembros". Esto significa que la competencia que tendría la Unión Europea en este campo sería "concurrente" o "indistinta» respecto a las competencias del Estado, que no quedan mermadas ni un ápice ${ }^{16}$.

El Derecho Comunitario derivado, por su parte, acoge normas como el reglamento sobree exportación de bienes culturales y la Directiva sobre restitución de bienes culturales ilegalmente exportados ${ }^{17}$. Ambas normas presuponen que, aun considerando a las obras culturales una "mercancía», ésta no está sometida al "libre comercio».

3.C. De entre las normas internacionales de carácter bilateral existentes en materia de cultura, sobresale por su importancia el Acuerdo entre el Estado Español y la Santa Sede sobre enseñanza y asuntos culturales, firmado en la Ciudad del Vaticano el 3 de enero 1979. En dicho acuerdo se contiene un importante precepto, el Artículo XV, según el cual, "la Iglesia reitera su voluntad de continuar poniendo al servicio de la sociedad su patrimonio histórico, artístico y documental y concertará con el Estado las bases para hacer efectivos el interés común y la colaboración de ambas partes, con el fin de preservar, dar a conocer y ca-

${ }^{16}$ Cfr. sobre este precepto el comentario de María Concepción BarRero RodRíGUEZ, "El nuevo precepto europeo en defensa del patrimonio cultural. El artículo 128 del Tratado de la Comunidad Europea", en P. Chiti (coord.) Beni culturali e Comunità Europea, cit., p. 221 ss.

17 Reglamento (CEE) 3911/92, del Consejo, de 9 de diciembre de 1992, relativo a la exportación de bienes culturales (DOCE L-395). Directiva 93/7/92, del Consejo, de 15 de marzo de 1993, relativa a la restitución de bienes culturales que hayan salido de forma ilegal del territorio de un Estado miembro (DOCE L-74). 
talogar este patrimonio cultural en posesión de la iglesia, de facilitar su contemplación y estudio, de lograr su mejor conservación e impedir cualquier clase de pérdidas en el marco del artículo 46 de la Constitución". A estos efectos, y a cualesquiera otros relacionados con dicho patrimonio, "se creará una comisión mixta en el plazo máximo de un año a partir de la fecha de entrada en vigor en España del presente Acuerdo".

3.D. Dado que los tratados internacional ratificados por España forman parte del ordenamiento interno español, según nos dice el art. 96.1 CE esto nos lleva a considerar tres cuestiones.

En primer lugar, que, en virtud de lo dispuesto en el Pacto Internacional de Derechos Económicos, Sociales y Culturales existe un «derecho», infraconstitucional, pero válido en el ordenamiento español a "participar en la vida cultural», tanto más importante cuanto que el "acceso a la cultura" en la Constitución es sólo un "principio" y la "participación" en la "cultura" un "fin del Estado", pero no un derecho.

En segundo lugar, en virtud de lo dispuesto en el Tratado CEE, las medidas de fomento en materia de cultura y patrimonio cultural son válidas, tanto se adopten por el Estado (que debe ser entendido en sentido global, es decir comprensivo de sus entes territoriales) como por la propia Comunidad Europea.

En tercer lugar, de acuerdo con lo previsto en los tratados internacionales suscritos en el marco de la UNESCO y del Consejo de Europa, se introducen «mandatos» al Estado Español para que consiga los objetivos perseguidos en esos convenios internacionales. El cumplimiento de estos mandatos plantea el problema de qué ocurre cuando la Comunidad Autónoma ha asumido la competencia "exclusiva» en materia de protección del patrimonio cultural. A este respecto hay que atenerse a lo previsto en la Constitución y los Estatutos de Autonomía. Pueden darse así tres supuestos. El primero es que el Estatuto disponga expresamene que la CA ejecute en su territorio las normas internacionales que afecten a su competencia. Es lo que ocurre en el caso de la CA de Castilla y León (art. 38.4 EACyL). El segundo sería que el correspondiente Estatuto (el de Galicia, por ejemplo) careciese de tal cláusula. En este último caso se viene entendiendo que, a pesar de la falta de tal previsión estatutaria, la CA vendría obligada a ejecutar lo dispuesto en tal norma internacional en tanto en cuanto esa obligación recae sobre la competencia asumida como "exclusiva" de protección del patrimonio.

En cuarto lugar, en el caso del convenio con la Iglesia Católica, la norma internacional que establece la creación de una "comisión mixta" 
se traduce en la posibilidad de que la CA que ha asumido la competencia en materia de "patrimonio cultural» cree su propia "comisión mixta" con la Iglesia Católica. Esto es lo que han hecho las leyes autonómicas sobre patrimonio cultural (así, la de Castilla y León ${ }^{18}$ ).

\section{EL PATRIMONIO CULTURAL Y LA ESTRUCTURA TERRITORIAL DEL ESTADO}

Según el art. 137 CE «el Estado se organiza territorialmente en municipios, en provincias y en las Comunidades Autónomas que se constituyan". La estructura territorial del Estado afecta de forma importante al fenómeno de la cultura y de la protección del patrimonio cultural. Como veremos, la estructura territorial.

4.A. En esta materia de "cultura", se hace preciso delimitar las competencias del Estado y de las CCAA. Por lo que hace al Estado central, el art. 149.1.28 C.E. señala como competencia exclusiva del Estado la «defensa del patrimonio cultural, artístico y monumental español contra la exportación y la expoliación; museos, bibliotecas y archivos de titularidad estatal, sin perjuicio de su gestión por parte de las Comunidades Autónomas". A ello se le añade el mandato según el cual «el Estado considerará el servicio de la cultura como deber y atribución esencial y facilitará la comunicación cultural entre las Comunidades Autónomas, de acuerdo con ellas» (art. 149.2 C.E.). Por su parte, las CCAA, además de asumir la competencia sobre gestión del patrimonio implícitamente permitida por el art. 149.1.28 CE, pueden asumir competencia en las materias de «museos, bibliotecas y conservatorios de música de interés para la Comunidad Autónoma, "patrimonio monumental de interés de la Comunidad Autónoma" y "fomento de la cultura, de la investigación y, en su caso, de la enseñanza de la lengua de la Comunidad Autónoma» (art. 148.1.15 a $17^{\circ} \mathrm{CE}$ ).

La interpretación conjunta de estas normas ha sufrido una variación sustancial de forma que el TC ha modificado su jurisprudencia inicial hasta llegar a un desapoderamiento sustancial del Estado en materia de "cultura".

En un principio, el TC sostuvo que la cultura "es algo de la competencia propia e institucional, tanto del Estado como de las Comunidades Autónomas». De esta suerte, el TC estimaba que había una "comLeón.

${ }_{18}$ Art. 4.2 de la ley 12/2002, de 11 de julio, de patrimonio de cultural de Castilla y 
petencia concurrente" del Estado y las Comunidades Autónomas en materia de cultura. Conurrían así la competencia para una acción autonómica específica, con la del Estado en el área de preservación del patrimonio cultural común, pero también en aquello que precise de tratamientos generales o que haga menester esa acción pública cuando los fines culturales no pudieran lograrse desde otras instancia. Esta tesis viene avalada por el hecho de que el propio texto del precepto, que pone el acento en el servicio de la cultura como "deber" y "atribución esencial» del Estado ${ }^{19}$. A esto cabría añadir que cuando, en materia de cultura, después de reconocer la competencia autonómica, se afirma una competencia estatal, ello no se hace en el catálogo de competencias estatales exclusivas del art. 149.1, sino en un lugar muy particular: el apartado 2 del artículo 149, lo que es tanto cómo decir que el régimen jurídico del reparto de las competencias del art. 149.1 no se aplicaría al 149.2 que tendría una regulación distinta.

Ahora bien, en un momento posterior, en su importante STC $17 / 1991^{20}$, el Tribunal dijo que, a pesar de la competencia que se reconoce al Estado, la competencia ejecutiva o de "gestión" corresponde siempre a las CCAA. EI TC reconoció que la materia relativa al patrimonio histórico-artístico se integra en la más amplia que se refiere a la cultura por lo que consideraba fundamentada a la potestad del Estado para legislar en aquélla. Sin embargo, estimó que no cabía extender la competencia estatal a ámbitos no queridos por el constituyente, por efecto de aquella incardinación general del patrimonio histórico artístico en el término cultural, pues por esta vía se dejarían vacíos de contenido los títulos del bloque de la constitucionalidad que se limitan a regular una porción definida del amplio espectro de la misma. Existe en la materia que nos ocupa un título de atribución al Estado definido en el art. 149.1.28 C.E. al que se contrapone el que atribuye competencias a las Comunidades fundado en los Estatutos de Autonomía. De ahí que la distribución de competencias Estado-Comunidades Autónomas en cuanto al Patrimonio Cultural, Artístico y Monumental haya de partir de aquel título estatal pero articulándolo con los preceptos estatutarios que definen competencias asumidas por las Comunidades Autónomas en la materia. El Estado ostenta, pues, la competencia exclusiva en la defensa de dicho patrimonio contra la exportación y la expoliación, y las

19 SSTC 84/1983, de 24 de octubre (ponente: ), FJ 20; 49/1984, de 5 de abril (ponente: Arozamena) FJ 6; 157/1985, de 15 de noviembre de 1985 (ponente: Díez-Picazo), FJ 4; 106/1987, de 25 de mayo (ponente: Rodríguez-Piñero) FJ $2^{\circ}$.

${ }^{20}$ La crítica más amplia de esta sentencia se debe a Juan Manuel Alegre ÁviLA, Evolución y régimen jurídico del patrimonio histórico, Ministerio de Cultura, Madrid, 1994, t. II, p. 759 ss. 
Comunidades Autónomas recurrentes en lo restante, según sus respectivos Estatutos; sin que ello implique que la eventual afectación de intereses generales o la concurrencia de otros títulos competenciales del Estado en materia determinada no deban también tenerse presentes como límites que habrá que ponderar en cada caso concreto. (Así los títulos que resultan, v. gr. de los números 6 y 8 del art. 149.1.) ${ }^{21}$. En efecto, si bien ex art. 149.2 C.E. el Estado puede destinar ayudas a un determinado sector de la cultura aunque, al no tratarse ya de una competencia exclusiva, el alcance de esta actividad genérica de fomento debe delimitarse con sumo cuidado. Para ello debe atenderse a la doctrina del TC en relación con la actividad estatal de subvenciones y ayudas. Según el TC, "el Estado puede consignar subvenciones de fomento en sus Presupuestos Generales, especificando su destino y regulando sus condiciones esenciales de otorgamiento hasta donde lo permita una competencia genérica, básica o de coordinación, pero siempre que deje un margen a las Comunidades Autónomas para concretar con mayor detalle la afectación o destino, o, al menos, para desarrollar y complementar la regulación de las condiciones de otorgamiento de las ayudas y su tramitación. Además, la gestión de estos fondos corresponde a las Comunidades Autónomas de manera, por regla general, que no puedan consignarse en favor de un órgano de la Administración del Estado u organismo intermediario de ésta. Se trata de partidas que deben territorializarse en los propios Presupuestos Generales del Estado si ello es posible o en un momento inmediatamente posterior, mediante normas que fijen criterios objetivos de reparto o mediante convenios de colaboración ajustados a los principios constitucionales y al orden de distribución de competencias ${ }^{22}$. En definitiva, por lo que aquí interesa, conviene retener que la regulación de las condiciones complementarias de otorgamiento, así como la tramitación y gestión de las ayudas ha de corresponder a las Comunidades Autónomas, siendo su gestión centralizada por el Estado la excepción, reservada para los casos en que resulte imprescindible para asegurar la plena efectividad de las ayudas dentro de la ordenación básica del sector y para garantizar iguales posibilidades de obtención y disfrute por parte de sus potenciales destinatarios en todo el territorio nacional, evitando al propio tiempo que se sobrepase la cuantía global de los fondos destinados al sector ${ }^{23}$. Así, pues, el Estado puede regular la concesión de ayudas y subvenciones para fomentar la difusión de la

21 STC 17/1991, de 31 de enero (ponente: Gabaldón), FJ $3^{\circ}$.

22 STC 13/1992, de 6 de febrero (ponente: Rodríguez Bereijo), FJ 8. b).

${ }_{23}$ SSTC 59/1995, de 17 de marzo (ponente: González Campos), FJ 5. A); 109/1996, de 13 de junio (ponente: Viver), FJ $6^{\circ}$. 
cultura común a todos los pueblos que lo conforman, pero no puede reservarse competencias de gestión salvo en los casos excepcionales que justifican su gestión centralizada, lo que habrá de parecer razonablemente justificado y deducirse sin esfuerzo de la naturaleza de la medida de fomento de que se trate ${ }^{24}$.

En segundo lugar, la restricción que lleva a cabo el TC sobre las competencias estatales es tal que incluso llega a privar al Estado del monopolio en la proyección "internacional» del patrimonio. Según el TC, ambos (Estado y Comunidades) y por títulos concurrentes en virtud del sistema de distribución de competencias, derivado del art. 149.2 C.E. la tienen para la difusión internacional del conocimiento del Patrimonio Histórico-Artístico y no cabe ni negarlo al Estado ni interpretar el art. 2.3 de la Ley de modo que genere para su Administración competencia exclusiva al respecto porque, no pudiendo llevarse a cabo por Ley la atribución de dicha competencia, esa interpretación iría contra las prescripciones constitucionales. Para estimar el precepto ajustado a la Constitución deberá interpretarse, pues, en el sentido de que las funciones de difusión internacional de los valores culturales de estos bienes en cuanto integrantes del Patrimonio cultural español podrán ser ejercitadas tanto por el Estado como por las Comunidades Autónomas que hayan asumido competencias respecto del patrimonio histórico y cultural, siempre que, como se ha dicho, no se trate de actos generadores de responsabilidades del Estado con terceros, sean políticas o económicas ${ }^{25}$.

Como conclusión, tras la jurisprudencia actual cabe decir que el Estado tiene un doble título. En primer lugar, una competencia que corresponde al Estado para la "preservación del patrimonio cultural común", así como "lo que precise de tratamientos generales o que no puedan lograrse desde otras instancias ${ }^{26}$. Junto a estas actividades, que competen en exclusiva al Estado, en segundo lugar, éste puede desempeñar también una actividad genérica de fomento y apoyo a las diversas manifestaciones culturales, aunque en este supuesto, deberá limitarse a prever las ayudas que estime pertinentes sin llevar a cabo otras actividades normativas y de gestión superpuestas o duplicadas respecto de las que corresponden a las Comunidades Autónomas con competencias en la materia de cultura ${ }^{27}$. Este marco, sin embargo, ha

${ }_{24}$ SSTC 13/1992, FJ 8. d); 330/1993, de 13 de noviembre (ponente: Viver), FJ 30; 213/1994, de 14 de julio (ponente: Cruz), FJ 4. b); 59/1995, FJ 5. A); 109/1996, FJ 5; STC 71/1997, de 14 de abril (ponente: Jiménez de Parga), FJ 4².

25 STC 17/1991, FJ $6^{\circ}$.

26 SSTC 49/1984, FJ 6; 157/1985, FJ 20; 106/1987, FJ 2; y 17/1991, FJ $3^{\circ}$.

27 STC 109/1996, FJ $4^{\circ}$; STC 71/1997, FJ $3^{\circ}$. 
sido interpretado por el TC de forma muy restrictiva respecto a la facultades del Estado, dando un amplio alcance a las competencias autonómicas.

4.B. La materia "cultura" también afecta a las corporaciones locales, en cuanto que también son "poderes del Estado". En efecto, dos disposiciones legales nacionales atribuyen a las entidades locales la tarea de apoyar la cultura: la Ley de Bases del Régimen Local (LBRL) y la Ley de Patrimonio Histórico ${ }^{28}$. De acuerdo con la primera, el Municipio ejercerá, en todo caso, competencias, en los términos de la legislación del Estado y de las Comunidades Autónomas, en las materias de "patrimonio históricoartístico" y "actividades o instalaciones culturales" (art. 25.2.e. y m. LBRL). La ley insiste en que "los Municipios pueden realizar actividades complementarias de las propias de otras Administraciones Públicas y, en particular, las relativas a (...) la cultura» (art. 28 LBRL). De acuerdo con la segunda, "los Ayuntamientos cooperan con los Organismos competentes para la ejecución de esta Ley en la conservación y custodia del Patrimonio Histórico Español comprendido en su término municipal, adoptando las medidas oportunas para evitar su deterioro, perdida o destrucción" (art. 7 de la Ley de Patrimonio Histórico). EI TC ha considerado que esta función de los Ayuntamientos es perfectamente acorde con la distribución de competencias establecida por la Constitución, ya que utal deber de cooperación con los órganos competentes de las Comunidades Autónomas o de la Administración del Estado no alude al régimen de competencias de unas y otras; no es sino una manifestación y aplicación concreta de lo que con carácter general se dispone en el art. 46 de la Constitución, al encomendar a todas las Administraciones Públicas la conservación y enriquecimiento del Patrimonio Histórico, Cultural y Artístico de los pueblos de España ${ }^{29}$.

\section{CONCLUSIÓN}

El estudio de la protección del patrimonio cultural en la Constitución Española tiene que partir de dos premisas fundamentales: en primer lugar, que el Estado actual es un "Estado de cultura» y, en segundo lugar, que España es algo más que un "Estado", es una "Nación" como bien dicen el Preámbulo y el art. 2 CE. Es una "Nación» que no es exclusi-

${ }^{28}$ Ley 7/1985, de 2 de abril, Reguladora de las Bases del Régimen Local; Ley 16/1985, de 25 de junio, del Patrimonio Histórico

${ }^{29}$ STC 17/1991, FJ 9 ${ }^{\circ}$. 
vamente una "nación política" o "nación-estado", sino que es también una "nación cultural» que a lo largo de los siglos ha ido generando un inmenso patrimonio. El olvido de estas premisas podría llevar a conclusiones tan absurdas como considerar al Palacio Real de la Monarquía Española como patrimonio cultural de la Comunidad Autónoma de Madrid (creada en 1983) o a que los bienes del patrimonio cultural procedentes de la monarquía hispano-visigoda (siglos VI-VIII) puedan ser gestionados por Comunidades Autónomas con nombres de reinos o principados cuyos nombres nacieron cinco siglos después.

Partiendo de estas premisas resulta verdaderamente inaceptable el desapoderamiento que ha llevado a cabo el Tribunal Constitucional Español de las competencias del Estado Central, como si España no fuera una entidad con su propia cultura y su propio patrimonio distinto del de sus Comunidades Autónoma. Esta doctrina resulta especialmente equivocada por cuanto no son las CCAA las que se han unido para crear el Estado, sino que es el Estado el que ha creado las Comunidades Autónomas. 